\title{
Electron-Dislocation Interactions at Low Temperatures
}

\author{
J. M. Galligan \\ Institute of Materials Science \\ University of Connecticut, \\ Storrs, Conn. 06268
}

1. Technical Progress Report.

In the first period of the present contract research has been initiated along the following lines. A. Growth and doping of lead crystals. B. Growth, purification of and removal of interstitials from niobium crystals. C. Construction and operation of low temperature tensile apparatus:

A. The growth and doping of lead crystals has involved constructing a furnace with the appropriate temperature gradient for growth of crystals. In addition graphite molds for growth of single crystals have been machined and tested. Single crystals of lead, with a starting purity of $99.999 \%$, have been grown in the present apparatus and the perfection of these crystals is being examined for the presence of substructure and other imperfections. These alloys are dilute alloys i less than $7 \%$ of $T 1$, Sn and $B i$ - so that special care is needed in preparing such alloys. Some deformation experiments are now being undertaken with these crystals, with special emphasis on a measurement of the electron drag on dislocations. In particular, measurements are being made on the concentration dependence of the electrat drag. The concentration of solute is being checked in these alloys by measurements of the chemical composition as well as the lattice parameter. The measured lattice parameter in the present alloys can be compared to the very careful measurements of Tyzack and Raynor ${ }^{7}$. These experiments are being conducted by $\mathrm{Mr}$. John Tregilgas and Mr. C. S. Pang. 


\section{DISCLAIMER}

This report was prepared as an account of work sponsored by an agency of the United States Government. Neither the United States Government nor any agency Thereof, nor any of their employees, makes any warranty, express or implied, or assumes any legal liability or responsibility for the accuracy, completeness, or usefulness of any information, apparatus, product, or process disclosed, or represents that its use would not infringe privately owned rights. Reference herein to any specific commercial product, process, or service by trade name, trademark, manufacturer, or otherwise does not necessarily constitute or imply its endorsement, recommendation, or favoring by the United States Government or any agency thereof. The views and opinions of authors expressed herein do not necessarily state or reflect those of the United States Government or any agency thereof. 


\section{DISCLAIMER}

Portions of this document may be illegible in electronic image products. Images are produced from the best available original document. 
B. Growth, purification of and removal of interstitials from niobium. In order to examine the influence of electron drag on dislocation motion in niobium, the niobium must be purified and as much of the interstitials impurities removed as is possible. The material will be purified the following way: niobium metal of nominal $99.9 \%$ purity will be first zone-refined at a relatively high partial pressure of oxygen, which lowers the carbon concentration. The material will be subsequently zonerefined under high vacuum conditions to remove oxygen and nitrogen interstitials. Finally the material will be annealed at a high temperature under high vacuum conditions. We have started on this procedure and we are growing crystals of niobium with a controlled partial pressure of oxygen. The controlled leak we have constructed for this purpose consists of a thin silver tube surrounded by an atmosphere of oxygen. The silver tube is heated to temperature which allows rapid diffusion of oxygen and the partial pressure of oxygen is controlled by a balance between the pumping rate in the vacuum chamber and the temperature of the sitver diffuser. At this time a limited number of crystals of niobium have been grown and we are establishing procedure for measuring the resistivity ratios of these and other niobium crystals. This work is being carried out by Mr. Jay F. Ely and Mr. S. Huang.

C. The tensile machine and associated equipment for the deformation experiments has been constructed and is operating satisfactorily. The tensile machine and associated dewars have the following provisions: Temperature range from approximately $1.8^{\circ} \mathrm{K}$ to $30^{\circ} \mathrm{K}$, the liquid helium portion of the dewar includes a superconducting magnet for switching 
the specimens from the normal state to the superconducting state during the deformation experiments. Additional design modifications of the present system, especially to perform experiments with copper are now underway; these we think will be completed in the next year or so. Since all of the students are involved in the deformation experiments they are all participating in this phase of the program. 


\section{References}

1. G. Tyzack and G. V. Raynor Acta Crystallographica, 7505 (1954). 